\title{
HRT and heart disease: problems and prospects
}

\author{
Angela H.E.M. Maas ${ }^{\mathrm{a}, *}$, Yolanda van der Graaf ${ }^{\mathrm{b}}$, \\ Yvonne T. van der Schouw ${ }^{b}$, Diederick E. Grobbee ${ }^{b}$ \\ a Department of Cardiology, Isala Klinieken, P.O. Box 10400, 8000 GK Zwolle, The Netherlands \\ b Julius Center for Health Sciences and Primary Care, University Medical Center Utrecht, Utrecht, The Netherlands
}

Received 23 June 2003; received in revised form 28 October 2003; accepted 31 October 2003

\begin{abstract}
The divergent findings of hormone replacement therapy (HRT) from observational and randomized clinical studies are summarized and reasons for the different results are postulated. Chronic use of HRT since menopause has no harmful effects on CHD event rate, while the initiation of therapy after a recent cardiovascular event causes an early increase in recurrent CHD events. Once endothelial dysfunction and atherosclerotic disease has developed, the starting of HRT promotes plaque instability, vascular inflammation and prothrombotic effects. The timing of HRT use since menopause is therefore crucial in the effectiveness and safety of HRT on the vascular system.

(C) 2004 Elsevier Ireland Ltd. All rights reserved.
\end{abstract}

Keywords: Hormone replacement therapy; Cardiovascular disease; Prevention

\section{Introduction}

Since the first secondary prevention trials were published in 1998, the prospect of hormone replacement therapy (HRT) to prevent atherosclerotic heart disease in post-menopausal women have changed dramatically [1-3]. Early harmful effects of HRT and lack of beneficial effects on coronary heart disease (CHD) event rates in high-risk women have challenged the beneficial results from observational studies in the past [4-7]. Recent results of the women's health initiative (WHI) study have further added to the debate by showing an excess in CHD events of 29\% (95\% CI

\footnotetext{
* Corresponding author. Tel.: +31-38-4245257; fax: +31-38-4542439.

E-mail address: a.maas@diagram-zwolle.nl (A.H.E.M. Maas).
}

$0.85-1.97)$, in healthy post-menopausal women aged 50-79 years [8]. Longer ( $>5$ years) use of combined HRT was also shown to raise the risk of developing invasive breast cancer with $26 \%$ (95\% CI $0.83-1.92$ ), leading to a net harmful effect on the long term. The authors of the WHI state correctly that the study was done in "apparently" healthy post-menopausal women. As endothelial function declines with ageing, long before clinical symptoms of atherosclerotic disease becomes manifest, one may argue whether the women included in the WHI were as healthy as they were assumed to be [9]. Two-thirds (67\%) of the women in the WHI were above 60 years of age, many with risk factors for CHD.

In the recently published data from 1636 female participants in the cardiovascular health study, a longitudinal study of cardiovascular risk factors in men 
and women over 65 years of age, a significant beneficial effect of HRT on reactivity of the arteria brachialis was restricted in healthy post-menopausal women. No such effect was seen in older women (>80 years), in women with documented CHD or in women with a combination of CHD risk factors [10]. The data from this observational study support the view that HRT might be more effective in maintaining vascular health than in restoring endothelial function when atherosclerotic lesions are already present [11].

\section{Chronic HRT use and CHD event risk}

A wealth of data from observational studies suggests a beneficial effect of HRT on the occurrence of CHD in post-menopausal women, amounting to a risk reduction of 35-50\% [12-14]. In most of these studies healthy post-menopausal women were followed without a history of CHD and with a relatively healthy lifestyle. The hormonal therapy was most often initiated in the direct peri-menopausal or post-menopausal period for the relief of menopausal symptoms. Recent meta-analyses of published observational studies, however, dispute their validity and re-emphasise the importance of healthy user bias to explain the results $[15,16]$.

In the randomised estrogen and prevention of atherosclerisis trial (EPAT) 199 post-menopausal women were studied, above 45 years of age, with no clinical evidence of coronary artery disease [17]. During 2 years of treatment carotid IMT measurements in women receiving $1 \mathrm{mg} 17 \beta$-oestradiol progressed at a slower rate compared to those on placebo. Progression of carotid IMT was equally reduced by estrogens and statins, no additive effects of both treatments was seen. This suggests that in healthy endothelium, oestrogen may inhibit atherosclerosis when HRT is started in the direct post-menopausal period.

Recent observational data from chronic HRT users who have experienced a cardiac event or a coronary intervention are concordant with the data from healthy women on HRT. In a retrospective analysis on 114,724 women $>55$ years of age, with confirmed acute myocardial infarction (AMI), from the National Registry of Myocardial Infarction-3 (NRMI-3) a reduction of $35 \%$ of in-hospital mortality was found in current HRT users compared to non-users [18]. Current users of HRT had fewer CHD events (12\% versus 35\%) and better survival (93\% versus $75 \%$ ) after elective PTCA and stenting compared to non-users [19-21]. Among women undergoing coronary artery bypass surgery, chronic HRT use was associated with a significant improvement in 5-year survival [22]. Importantly, most of these patients had started HRT in the direct post-menopausal period for the purpose of menopausal complaints. These findings may indicate that the vascular endothelium remains susceptible for the beneficial effects of estrogens on the vascular wall when started in the early years after menopause.

\section{Initiating HRT in CHD patients}

All randomised trials of HRT-use in women with an increased risk of CHD have failed to show any benefit on the vascular system [1-3]. Recent data from two more randomised angiographic studies, the WAVE-trial and the WELL-HART study, confirm the lack of benefit of HRT on the progression of coronary atherosclerotic lesions in women with documented coronary heart disease [23,24].

In the heart and estrogen/progestin replacement study (HERS) an increase of 52\% of cardiovascular events was seen in the first year after randomisation [1]. This excess in events rate appeared not to be present in those patients who were already on statin therapy [25]. It is assumed that initiation of HRT could destabilise coronary plaques, with a sharp rise in C-reactive protein levels, while statins may have a stabilising effect. The combined therapy seems to attenuate a detrimental effect of HRT on plaque stability. Many other studies have reported similar short-term harmful effects after initiating HRT in high-risk patients $[3,6,26,27]$. When HRT is started shortly after an acute MI, a significantly $44 \%$ higher risk of unstable angina pectoris, death and re-infarction is seen compared to chronic users and never users [28]. This early increase in adverse CHD events is attributed to both pro-inflammatory and thrombogenic effects of HRT. In a recent randomised, placebo controlled trial of 1017 women, 50-69 years of age, who had experienced a first myocardial infarction no early harm of initiating unopposed $17 \beta$-oestradiol was noted nor was any benefit seen in the frequency of re-infection or cardiac death after 2 years of treatment [29]. 
Importantly, the non-compliance to treatment was extremely high ( $>50 \%)$ after 1 year in the active treatment group, which weakens the power of this study.

\section{Time interval of starting HRT after menopause}

One important aspect in comparing observational data and randomised studies is the age of the patients and the time since menopause. Nearly all observational data have been derived from women who initially started HRT for the purpose of post-menopausal symptoms, when therapy was started in the early post-menopausal period. In the randomised HRT trials however, the age range of the women that were included was 50-79 years [30]. In these studies, women did not suffer from post-menopausal complaints anymore and started HRT 10-20 years or even more after the onset of menopause. As it is becoming more evident that HRT may maintain vascular health rather than restore endothelial function when atherosclerotic disease is already present, the interval of initiating HRT after cessation of the menstrual periods seems to be crucial in the effectiveness on the vascular system [23]. Until trials have been conducted with cardiovascular endpoints in women early after menopause, it remains uncertain whether HRT in this period of a woman's life can delay clinical signs of atherosclerotic disease.

\section{References}

[1] Hulley S, Grady D, Bush T, Furberg C, Herrington $\mathrm{D}$, Riggs B, et al. Randomized trial of estrogen plus progestin for secondary prevention of coronary heart disease in postmenopausal women. Heart and Estrogen/Progestin Replacement Study (HERS) Research Group (see comments). JAMA 1998;280:605-13.

[2] Herrington DM, Reboussin DM, Brosnihan KB, Sharp PC, Shumaker SA, Snyder TE, et al. Effects of estrogen replacement on the progression of coronary-artery atherosclerosis. N Engl J Med 2000;343:522-9.

[3] Viscoli CM, Brass LM, Kernan WN, Sarrel PM, Suissa S, Horwitz RI. A clinical trial of estrogen-replacement therapy after ischemic stroke. N Engl J Med 2001;345:1243-9.

[4] Heckbert SR, Weiss NS, Koepsell TD, Lemaitre RN, Smith NL, Siscovick DS, et al. Duration of estrogen replacement therapy in relation to the risk of incident myocardial infarction in postmenopausal women. Arch Intern Med 1997;157:13306.
[5] Grodstein F, Manson JE, Colditz GA, Willett WC, Speizer FE, Stampfer MJ. A prospective, observational study of postmenopausal hormone therapy and primary prevention of cardiovascular disease. Ann Intern Med 2000;133:933-41.

[6] Grodstein F, Manson JE, Stampfer MJ. Postmenopausal hormone use and secondary prevention of coronary events in the nurses' health study. A prospective, observational study. Ann Intern Med 2001;135:1-8.

[7] Heckbert SR, Kaplan RC, Weiss NS, Psaty BM, Lin D, Furberg CD, et al. Risk of recurrent coronary events in relation to use and recent initiation of postmenopausal hormone therapy. Arch Intern Med 2001;161:1709-13.

[8] Writing Group for the Women's Health Initiative investigators. Risks and benefits of estrogen plus progestin in healthy postmenopausal women: principal results from the women's health initiative randomized controlled trial. JAMA 2002; 288: 321-33.

[9] Kleerekoper M. Lessons from the skeleton: was the women's health initiative (WHI) a primary prevention trial? Osteoporos Int 2002;13:685-7.

[10] Herrington DM, Espeland MA, Crouse III JR, Robertson J, Riley WA, McBurnie MA, et al. Estrogen replacement and brachial artery flow-mediated vasodilation in older women. Arterioscler Thromb Vasc Biol 2001;21:1955-61.

[11] Mikkola TS, Clarkson TB. Estrogen replacement therapy, atherosclerosis, and vascular function. Cardiovasc Res 2002;53:605-19.

[12] Stampfer MJ, Colditz GA. Estrogen replacement therapy and coronary heart disease: a quantitative assessment of the epidemiologic evidence. Prev Med 1991;20:47-63.

[13] Langer RD. Hormone replacement and the prevention of cardiovascular disease. Am J Cardiol 2002;89:36E-46E.

[14] Barrett-Connor E, Grady D. Hormone replacement therapy, heart disease, and other considerations. Annu Rev Public Health 1998;19:55-72.

[15] Humphrey LL, Chan BK, Sox HC. Postmenopausal hormone replacement therapy and the primary prevention of cardiovascular disease. Ann Intern Med 2002;137:273-84.

[16] Nelson HD, Humphrey LL, Nygren P, Teutsch SM, Allan JD. Postmenopausal hormone replacement therapy: scientific review. JAMA 2002;288:872-81.

[17] Hodis HN, Mack WJ, Lobo RA, Shoupe D, Sevanian A, Mahrer PR, et al. Estrogen in the prevention of atherosclerosis. A randomized, double-blind, placebo-controlled trial. Ann Intern Med 2001;135:939-53.

[18] Shlipak MG, Angeja BG, Go AS, Frederick PD, Canto JG, Grady D. Hormone therapy and in-hospital survival after myocardial infarction in postmenopausal women. Circulation 2001;104:2300-4.

[19] O'Keefe Jr JH, Kim SC, Hall RR, Cochran VC, Lawhorn SL, McCallister BD. Estrogen replacement therapy after coronary angioplasty in women. J Am Coll Cardiol 1997;29:1-5.

[20] Abu-Halawa SA, Thompson K, Kirkeeide RL, Vaughn WK, Rosales O, Fujisi K, et al. Estrogen replacement therapy and outcome of coronary balloon angioplasty in postmenopausal women. Am J Cardiol 1998;82:409-13. 
[21] Khan MA, Liu MW, Singh D, Pal A, Chio FL, Lawson $\mathrm{D}$, et al. Long-term (three years) effect of estrogen replacement therapy on major adverse cardiac events in postmenopausal women after intracoronary stenting. Am J Cardiol 2000;86:330-3.

[22] Sullivan JM, El Zeky F, Vander ZR, Ramanathan KB. Effect on survival of estrogen replacement therapy after coronary artery bypass grafting. Am J Cardiol 1997;79:847-50.

[23] Hodis HN, Mack WJ, Azen SP, Lobo RA, Shoupe D, Mahrer PR, et al. Hormone therapy and the progression of coronary-artery atherosclerosis in postmenopausal women. $\mathrm{N}$ Engl J Med 2003;349:535-45.

[24] Waters DD, Alderman EL, Hsia J, Howard BV, Cobb FR, Rogers WJ, et al. Effects of hormone replacement therapy and antioxidant vitamin supplements on coronary atherosclerosis in postmenopausal women: a randomized controlled trial. JAMA 2002;288:2432-40.

[25] Herrington DM, Vittinghoff E, Lin F, Fong J, Harris F, Hunninghake D, et al. Statin therapy, cardiovascular events, and total mortality in the Heart and Estrogen/Progestin Replacement Study (HERS). Circulation 2002;105:2962-7.

[26] Grady D, Hulley SB. Postmenopausal hormones and heart disease. J Am Coll Cardiol 2001;38:8-10.

[27] Hemminki R, McPherson K. Value of drug-licensing documents in studying the effect of postmenopausal hormone therapy on cardiovascular disease. Lancet 2000;355: $566-9$.

[28] Alexander KP, Newby LK, Hellkamp AS, Harrington RA, Peterson ED, Kopecky $S$, et al. Initiation of hormone replacement therapy after acute myocardial infarction is associated with more cardiac events during follow-up. J Am Coll Cardiol 2001;38:1-7.

[29] The ESPRIT team. Oestrogen therapy for prevention of reinfarction in postmenopausal women: a randomized placebo controlled trial. Lancet 2002; 360: 2001-08.

[30] Manson JE, Hsia J, Johnson KC, Rossouw JE, Assaf AR, Lasser NL, et al. Estrogen plus progestin and the risk of coronary heart disease. N Engl J Med 2003;349:523-34. 